\title{
Mature students, transformation and transition
}

\section{Samantha Jane Broadhead, (2018) "Mature students, transformation and transition", Education + Training, https://doi.org/10.1108/ET-02-2018-0035}

The purpose of this article is to argue for a transformative education that draws upon the capacity of students to practice phronesis. Phronesis or practical wisdom is an intellectual virtue of deliberation based on the desire to act in the best interests of the self and others. The stories told by Eliza, a mature student, are analysed through narrative inquiry revealing her deliberations about her education. This approach uses narrative as a means of capturing experience and it is argued that the ability to narrate one's own experience is integral to phronesis. Conclusions drawn from this study are not easily turned into generalisations or 'truths' as they are contingent on the contexts in which the narratives were produced. Narrative is a representation of experience which is mediated by the social and cultural positions of the narrators and their audiences. This study found that mature students were adept at phronesis; making courageous decision to leave their careers and re-enter education to improve their lives for themselves and their families. However, the way that higher education is structured meant that they did not always deliberate well. Fear, frustration and anxiety impeded the practice of phronesis. The implications for educators are that they should think about strategies for teaching students to deliberate well for them and others and instances of phronesis should not be curtailed but celebrated. The value of this approach is that it aims to promote the capacity of wise deliberation in students so they become agents in their own transformation.

\section{Introduction}

The national policy of widening participation exists within a competitive and uncertain higher education culture and at the same time receives decreasing governmental support; questions have emerged around its effectiveness in helping to retain students and support their success (Bhagat and O'Neil, 2011; Liasidou, 2012). The impact of this on those who dream of becoming artists and designers and are at the same time labelled by higher education institutions as mature students needs to be examined. This article analyses the narratives constructed by and between Eliza, a post-Access to HE student, and myself, the inquirer that represent some of her experiences during her BA (Hons) Textile course. This case study was part of a longitudinal study (2011-15) that sought to investigate the 
experiences of post-Access students in art and design higher education. The participants were studying on a range of creative degree programmes in various institutional contexts. Narrative inquiry was used to show the ways in which students reflected on and took stock of their educational journeys.

The analysis drew upon some of the notions concerned with phronesis (prudence or practical wisdom). This was because the participants' narratives often recounted how they had made decisions in the past, for example that they had decided to risk financial and emotional security by taking part, firstly, in Access to HE and later art and design higher education later in life. These difficult decisions were made so that they could ultimately live a better life, working in the creative industries. Also, the processes of deliberation about acting well on the programme of study were made visible through the post-Access to HE students' stories and this seemed to be an important part of their learning experiences. Aristotle claimed that only a person of experience could practice practical wisdom, and a young person was unlikely to have extensive life experience, (Aristotle, 1953, Nicomachean Ethics, Book VI, Chapter 8). Did mature post- Access students use in order to navigate through the challenges of higher education? This discussion recounts some of the critical incidents within Eliza's story where I noticed evidence of phronesis or at some points the absence of wise judgement. I suggest that within the context of higher education mature adults sometimes made poor decisions leading them to act in ways that continued their sufferings. This was because they did not always exercise their potential to act with prudence, (Aristotle, 1953, Nicomachean Ethics, Book VI, Chapter 5). The importance of students acting well because of friendship can also be gleaned from Eliza's account. This article argued that friendship in the sense of deliberating and acting well for others was also an important aspect of phronesis as practised by mature and younger students.

\section{Theoretical framework: transition and transformation}

The examination of the experiences of post-Access to HE students within art and design higher education also involves the examination of transition and life change. Many of the participants had not gone to university before and so they were being confronted with new learning contexts.

The notion of transition has been used to understand people's experiences in education. Transitions could be seen as processes of change to new contexts or life circumstances. Zittoun (2007, p.195) said, "Usually transitions follow ruptures - modifications of what is taken for granted in a person's life - which can be due to various causes." Early work on 
transitions looked at how young people made the transition from school to work (Goodwin and O'Connor, 2007). However the scope of this study was how mature students experienced higher education. Most of the literature on transition of young people 'to' and 'in' HE identified the induction period and the first year as being significant (Kane et al., 2014; Stagg and Kimmins, 2013; Thomas, 2012; Harvey et al., 2006). Much of the literature focused on the experiences of traditional age at entry students where it was assumed they would be coming from doing ' $A$ ' levels at school or a sixth form college (Hudson, 2009; Jackson, 2003). Often transition to higher education was seen as part of becoming an adult; for middle-class students in particular (Thomas, 2012; Pampaka et al 2012; Christie et al., 2005). 'Good' or 'successful' transitions were often seen desirable by institutions because they led to increased retention and academic success (Thomas, 2012; Harvey et al., 2006).

A sense of belonging experienced by students has been identified as a factor which improved retention in schools and in higher education (Goodenow, 1993; Baumeister and Leary, 1995; Thomas, 2012). Friendship between students is seen as one way in which a sense of belonging could be developed as well as providing informal support systems, (Tinto, 1993; Thomas, 2002; Wilcox et al., 2005). Duckworth (2014) has also described how friendship could be a means of helping students cope with any symbolic violence they may be subject to that comes from an unwelcoming or even hostile institutional environment.

It is possible to interrogate the notion of transition as a single event or crisis point that constructs a deficit model to understand student's experiences of higher education. The experiences of mature students within higher education suggest that transition needs to be understood in a different way as they bring with them capacities which should be valued by those in higher education.

Alternative understandings of going to university as part of the constant life changes that happen in people's lives are relevant to the experiences of mature students.

Within the context of lifelong learning Ecclestone (2009) explored three perspectives on transition (identity, agency and structure). It was argued that thinking about transitions , "not only risk pathologising transitions by depicting them as unsettling, disruptive, daunting, anxiety inducing and risky but also create normative assumptions about how best to manage them," (Ecclestone, 2009, p.23). The negative aspects of transition were often 
the focus of the debates and it was assumed that people needed help to get through periods of uncertainty and change like going to university. This perspective, "erases the positive effects of difficulty, challenge and overcoming problems and risks attributing 'problems' to particular groups so that people become a problem to be supported and managed effectively," (Ecclestone, 2009, p.23).

Similarly O'Shea (2014) has carried out extensive research on the experiences of first-in-thefamily students at the University of Wollongong, Australia. Within this particular institution people from disadvantaged groups were applying and gaining entry to the university, however, the retention of these students was not very good; the attrition rates being between 18 and 25\%. O'Shea (2014) was critical of what she described as the deficit model that was often applied to students from certain social groups. Instead she used a concept developed from critical race theory by Yosso (2005); It was argued that although first-in-thefamily students may not have the white, middle-class cultural capital of traditional students they did come with other kinds of capitals (aspirational, navigational, social, linguistic, familial and resistant). O'Shea (2014) argued that students and the institution should recognise and value these attributes that would improve the educational experience for everyone. Implicit in O'Shea's argument was that seeing the idea of transition into higher education as being about a change from one identity to another could devalue the attributes the student already had.

Gale and Parker (2014) argued for 'transition-as-becoming' as a rejection of the previous approaches to thinking about transition. It was also the rejection of 'transition' as a useful concept altogether because it failed to capture the fluidity of people's lives and the ways they learn. Rather than transition being viewed as linear and smooth; the lived experiences of students was understood to be more complex. There was an acceptance of the interdependence of 'public issues' and 'private troubles'. Anxiety and risk was seen as part of day-to-day life rather than attributed to a rare and special event. It was acknowledged that,

...transitions can lead to profound change and be an impetus for new learning, or they can be unsettling, difficult and unproductive. Yet, while certain transitions may are unsettling and difficult for some people, risk, 
challenge and even difficulty might also be important factors in successful transitions for others. (Ecclestone, Biesta and Hughes, 2010, p.2)

Gale and Parker (2014) claimed that a focus on induction or individual development modes of transition implied assimilation and integration of students into the dominant culture of the university, which inevitably privileged some students from middle-class backgrounds over under-represented students. However, the 'transition-as-becoming' approach called for an institutional discourse of adaptation, where the diverse cultural capital brought by students to higher education is affirmed. Thus higher education knowledge systems and practices should become more open and flexible.

For post-Access to HE students the transition to higher education should be seen as a slow, continuous process of becoming where they feel that they belong to the institution; that they 'fit in' and are studying in the best place for them. Preparing students for higher education through an access course; which is traditionally delivered in further education (Parry, 1990) aims to give students the academic tools to succeed. However, this alongside an induction period at the beginning of the degree can only be the start of a longer process. The experiences students have interacting with different forms of pedagogy, assessment, staff and modes of communication are mediated not only by their previous educational histories, but also by the culture of higher education itself.

For some commentators the purpose of access routes into higher education is not just about developing the individual or even groups but to act as a catalyst for community development and to change HE itself (Parry, 1989; Connelly, 1991). Does the inclusion of a diverse range of students lead changes in pedagogy and assessment within higher education? Or do student continue to be seen as problems which need to be solved, where role of an Access courses to ensure that the student is transformed into someone who can seamlessly transition into higher education?

\section{Methodology}

This article draws upon the accounts of post-Access students who took part in a longitudinal study (2011-2015) that sought to record their experiences as they studied their degrees in art and design. Eight students participated and this entailed meeting with me (the researcher) twice a year during the 
duration of their higher education. The students had control over what elements of their education they could talk about. The approach used was based on narrative inquiry, rather than prescribed interview questions, (Clandinin and Connelly, 2004; Butler-Kisber, 2010). Brookfield (1995) stated that educational research should start with the students themselves and that teachers should try to see the educational experience through their eyes. Coffield (2006) has argued that students should be engaged in conversations about education not just answering but asking questions about their experiences. All the students had achieved an Access to HE diploma at level three and had progressed to a variety of art and design degrees, including textiles, visual communications and fine art. Due to the entry qualifications to higher education held by these students not being ' $A$ ' levels and a Foundation Course, they could be perceived by their institutions as being 'non-traditional' (Hudson, 2009; Penketh and Goddard, 2008; Burke, 2002). They also tended to be mature students with a variety of backgrounds and life experiences (Broadhead, 2014; Busher et al., 2012).

Nine participants agreed to take part in the project. Three of them had no qualifications before they achieved their Access to HE diploma; one student had professional qualifications at level seven (postgraduate study). Of the nine one student dropped out of her course in millinery after the first interview. Of the remaining sample five participants had chosen to study at the art college full time, these were two women and three men. Their ages ranged from late 20 s to mid-50s. Three students had chosen to study at a local Higher Education Institute (HEI) these were all women in their late 40s to early 50s. Two had decided to study part time and one full time. One of the part-time students was the only none-white student in the sample.

All the participants identities were protected by the use of pseudonyms and the institutions where the students studied were anonymised. Informed consent was sort by the researcher throughout the project.

For the purposes of this article Eliza's narrative has been treated as a case study in order to illustrate some of the tensions between acting with practical wisdom and higher education in art and design. Eliza was a post-Access student studying on a BA (Hons) Textile degree course. Eliza's textiles course included opportunities for learning knit and stitch as well as printing and Computer Aided design (CAD). Her story was chosen because of the way the intersections of race, gender and age constructed Eliza as a 'non-traditional' student. What was significant about Eliza's story was the way her part-time mode of study impacted on her learning and experience of higher education. This is of interest when 
the considered in the light of comments made by Professor Les Ebdon, Director of Fair Access to Higher Education.

"As part-time students are more likely to be from disadvantaged and underrepresented groups, this continuing decline should be a profound concern to all those involved in widening participation. The opportunity to study part-time can open doors and change lives, especially for people who were not able to go straight into higher education after school. (Ebdon, 2018: 1)

The first two years of her course is at level four, the modules include an introduction to creative practice and experimentation; design research and the exploration of textile design contexts. There is a clear focus on employability and students are encouraged to take part in overseas study, work placements and trips to professional trade fairs and studios.

Level five, also delivered across two years, continues with a more in-depth analysis and practice of market-led design; trends and innovation; research into the textile professional context; research into historical and contemporary critical issues and design as a practice. The modules build upon existing skills whilst utilising creativity in an innovative and professional manner.

The final two years at level six allows students to pick their own personal creative pathway. Modules include a final major project with is in keeping with other art and design courses. The students also write a critical appraisal relating to their work and are also required to think about the promotion of their final degree collection. Students are expected to utilise a combination of creative intuition and acquired technical skills such as CAD.

Eliza was the only black student in the group of participants and was in her early 50 s when the study began. Even though she had a very successful professional career she also wanted to develop her creativity in textiles (she was an accomplished dress-maker). She had explored textiles and printmaking on her Access to HE course and so decided to do this as a degree. Studying her degree part-time meant she needed to plan her schedule well in advance so it was important she had accurate, timely, information about deadlines. She needed to do the course part-time so she could continue to be in employment. Eliza elected to study her degree at a different institution to where she did her Access course; this was partly due to the fact that her chosen higher education institution had a part-time mode of study. 


\section{Findings}

The next section discusses Eliza's story at various points during her educational journey between June 2013 and February 2015. She was a part-time student and this mode of study proved to an important aspect of how she experienced her education. Eliza met with the researcher and reflected on her learning experiences during her textiles degree at the end of the first year; half way through her second year and half way through her third year. These meetings covered learning achieved at level four and level five.

End of the first year; level 4

Although Eliza was more playful and experimental in her work when studying on her Access to HE course, she seemed to have become inhibited. The way she had to balance her work and study has meant that she had to be strategic in how she used her time. Eliza's thoughts about her learning reveal how she deliberated about her education and how to manage her situation.

Researcher: You used to experiment in Access didn't you?

E: Yes, yeah but for some reason I noticed I sometimes get a bit of a block. I think a lot of it is better than last year and hopefully going into level five (which actually does count now). I think it's a certain amount that goes towards your final mark or something. So I know l've got to be a bit pragmatic at the same time I got to really put a lot more work into it than I have been. I have done the Wednesdays and if it's the open access as well I'm there all day 'til about 7 o'clock at night making use of all the facilities. This year I had to work half a day extra at work so I was working 3 1/2 days; instead of doing two days I was doing $11 / 2$ days on my course. It couldn't be helped it was just one of those things, it helped to pay for the course and again since I was being pragmatic about it all. Every now and again I asked, "Oh what am I doing this for, why am I doing this?' (Researcher and Eliza, June 2013)

Because Eliza was not in university every day, she had to make sure she exploited the resources (print workshops, library, IT suite) when she could; so this would mean putting long hours in when she was in the studios and workshops. The amount of time she was able 
to donate to her course had decreased, even though she acknowledged she needed to produce more work. At the same time she was mindful that the marks in the second year contributed to her final degree. Eliza employed a pragmatic stance by seeing the positive aspects in a situation she had no control over. She told herself that the extra half-day at work would help pay for the course. There were clearly moments of doubt in Eliza's mind, perhaps the balancing act was just too difficult. In order to take pleasure in the playfulness of creativity, a person needs enough time and space to indulge themselves in materials and processes, without the added pressure of worrying about the learning outcomes or possible marks.

Marks were important to Eliza as they do to other students; but it seemed that getting to know her feedback and marks was not straightforward in her case:

This semester because I couldn't get in, I did say, I was going away I wouldn't be there to pick up the marks. So when I came back and went in, I asked, "Have you got my marks?" "No, not yet," and I said, "Well the external examiners are coming in so where are my marks?" So anyway I managed to get them verbally but I haven't seen the feedback sheets or anything like that. Maybe it's a bit naughty but I'm thinking, well, I want to complain about my marking. I thought it's not worth it because it doesn't go forward to anything it's probably me just being a bit naughty thinking how far can I go with this. (Eliza, June 2013)

Again Eliza constructed an internal narrative about what was the best course of action to take because of the difficulties she had getting her marks. Was Eliza being over critical of the academic staff? Were some of her expectations unreasonable or did she have a point when she was waiting to get her feedback? Eliza did entertain the idea of complaining, but did not do this lightly. After her deliberations she, again pragmatically, decided that the marks did not contribute towards her degree so it would not be worth the effort to complain. She also questioned her own motives for complaining: was she genuinely concerned or was this her exercising her power as 'a consumer' demanding a service she had paid for? Williams (2013, p.7) has talked about the construction of students as consumers and with this a perception that they now felt empowered to exert their rights. If Eliza did feel this sense of empowerment it had not come through in her narrative so far and in this instance she had 
decided not to act on her sense of injustice. This appears to be an example of Eliza deliberating on the best course of action for herself and the staff; it demonstrates how she thought about some of the issues she experienced in her education.

Half way through year two; level four

Eliza had begun to seriously consider leaving her course. The problems that she had been having at level four had not been resolved.

I am thinking about leaving this ridiculous course. I was looking forward to the second year (moving up to the level 5 now as it is a part-time course). I was so looking forward to doing a new brief as I had done quite well on the previous one. But it was not a positive brief. Our six designs were to be given to an American firm - six designs - so I knew I had to produce the work. But my sketch book wasn't progressing or up-to-date as I was working hard in the print room. I knew it [the sketchbook] was supposed to follow your working process. The tutor told me to leave it to the end - but I wasn't sure about that. The last project I did really well, but I didn't really understand visual research - every time I was stuck I asked for help. (Eliza, February, 2014)

Eliza was able to ask for help and could identify areas that she needed further clarification on but she still seemed unconfident and uncertain in her design practice. The tone of this account had lost the positive aspects that were part of the previous year's meeting. She seemed to be unable to prioritise the tasks, focusing on the doing and making rather than the documentation of the process and the reflective thinking that should be seen in her sketchbook. Was this an issue related to part-time study?

So the tutor said come in early and I will talk to you. So I did I came in at 9.30 when we start at 10.30 , but she told me she couldn't speak to me as she had to go to a meeting. So I tried to teach myself CAD [computer aided design] and just got on preparing my screens. I went back to the learning outcomes and didn't do any samples. I felt frustrated I didn't want to do it. One of the younger students was so sweet they put together 'a how to do CAD' guide for me. (Eliza, February, 2014) 
Eliza did act with wisdom to some extent as she was not averse to asking for help when she required it. For example, she was struggling with computer aided design (CAD) and she told me that, 'One of the younger students was so sweet they put together a how to do CAD guide for me.' This was an example of virtuous and unselfish action by another student designed to help a person in need. However, common themes within Eliza's story were about her frustrations with the systems of communication used to tell students about their assessment. Briefs (the assignments by which art and design work by students is assessed) were not written specifically for part-time students so they had difficulty in understanding the volume and quality of work they should produce. But also communication with staff had proved to be difficult, especially as a part-time student Eliza was not in the studio as often as she would have liked and so was not freely available to talk to staff. Eliza was clearly frustrated and again back to the learning outcomes on the brief to see if they would help her. It was clear that the learning outcomes, on their own, could not help and Eliza needed the support of her tutor:

I stayed late and I knew two screens wouldn't be enough so I ended up doing 34 screens. But she [the tutor] kept saying I would have to manipulate them and I kept saying, "I don't understand." The upshot was I only got $48 \%$ and I got $55 \%$ on my Techniques and Processes (T and P). Last time I got 75\%. It so complicated so I went back to look at my feedback I got 56 for my visual research and 51 from my T and P and I still don't understand their marking system. But I still produced six designs. I didn't know what I was doing or where I went wrong. I sent an email but then staff went defensive. I bullet pointed the questions, I wasn't blaming her. But when I got to the meeting it wasn't her but her line manager and the head of the course. We had this meeting and I still don't know where I went wrong. How do you learn something in two hours a week especially if you don't have the CAD packages at home? I'll just do it my way. (Eliza, February, 2014)

In one sense Eliza was doing everything right she was using the learning outcomes as her guide; asking for help and re-reading her past feedback to try and discover what she was failing to do. Getting a mark of $75 \%$ previously was not useful if the student did not understand why they got such a high mark. It seemed that one of problems was - how could 
Eliza learn CAD? -which would be difficult to learn at home unless one was very confident and proficient in IT skills? The tutor had called upon other staff members to answer Eliza's questions. Reading between the lines this member of staff seemed reluctant to communicate with Eliza or was unable to clarify what Eliza needed to do to succeed. Perhaps the part-time route did not provide enough time and resources for her to learn? There still seemed an air of ambiguity in the assessment process. Information should be made explicit, some careful thought by educators on what information students needed and the best way to communicate it would have benefited the situation.

Half way through year three; level five

A year later Eliza was still questioning whether or not she belonged on the course.

E: I got my last lot of work back which was not too bad you know. I did talk to the tutor and basically said, "You know I'm not sure if this is for me and you know really I'm not enjoying it and if I'm spending two days of my life for the next three years, it's not a good use of my time really." And she was a bit shocked and bit surprised and basically said to me, if I could get through the next year (which is this coming year), things will be a lot easier in the final two years because it's much more bio-self-direct stuff. (Eliza, February 2015)

Eliza had thought about her time-commitment and was making a rational decision about whether to stay or leave. She was asking the tutor about it so she seemed to be taking into account the opinions of others. The way that Eliza was weighing up her options may suggest that she was drawing on her practical wisdom in order to make the best decision for herself. Maybe it would have been best for Eliza if she left the course. However, the tutor was surprised that Eliza had considered dropping out, so it could be assumed that she had not noticed how frustrated Eliza had been and this supported the notion that communication had been very difficult. Eliza had been encouraged to stay, to 'get through' the second year as if it would be a trial with the promise that the final two years at level six would be easier because they were more self-directed. The best thing for the member of staff and the institution was that a student did not leave the course. There was no suggestion that the course would change in order to address some of the problems Eliza had been having. Why would level six be easier than level five? Eliza had felt frustrated when working at levels four 
and five so there was a danger that this would continue at level six. Although the tutor had been encouraging, the underlying problems were not really thought about in depth or addressed. The tutor had not listened to what Eliza was unhappy about and assumed it was do with finding the course difficult when actually the issues had been to do with communication, misunderstanding and exclusion. Again Eliza's deliberations are captured by her story; she is attempting to make a wise decision so she can act for her best interests. By seeking a tutor's opinion she shows how she is open to other perspectives so she can weigh up her options. Did the tutor in this instance demonstrate phronesis; they may have believed they were acting in Eliza's best interests, but did not explore the issue fully to get a sustainable solution to the problems she was having.

Eliza decided to stay for another year and was attempting to accept that she would have to keep being pro-active in getting the support she needed as a part-time student. Liz was another part-time mature student who was studying on a fine art undergraduate course; she was also the department's student representative. Her role was to communicate with the staff about any issues the students were having with their studies. Eliza asked for Liz's help in requesting that staff populate the VLE with relevant and current information.

E: So now we've started this new brief and again it starts. I need to start now; sit down and go through everything. So again I emailed last week and said, "Can you let me know if I need to bring anything this Friday nothing is on the Moodle? Do we have our own [part-time] brief on the internet?" Liz is now the course rep. so she's actually sent an email to the tutors to say, "You know nothing is on the Moodle. Just read the brief today and it says very clearly that a lot of information will be put on the Moodle. We're expecting you to do that." I went on Moodle again today - nothing there. I kind of know what I need to do. I know that l've got to start doing 'trend forecasting'. I just need to have the designs ready to go by Friday. Also I'm working at night so I'm thinking, "Right I need to get this done and it's quite an interesting brief or not as the case may be, about being innovative; innovative through fabrics and I don't understand what that means." (Eliza, February 2015) 
The Moodle or VLE was very important for students who were part-time as this could be a means of including people who were not able to attend certain taught sessions. However, as had happened previously, Eliza and Liz did not get what had been promised and continued to work in the dark without brief or related information. In effect the request had not been heard. The student representative system can only instigate innovation and change if students are listened to and their concerns acted upon (Biesta, 2010: 122). Eliza said she 'kind of knows' what she needed to do, but then went on to say that she did not understand what the phrase 'innovative through fabrics' meant. More information on Moodle could have helped her respond to the brief well. The scenario that Eliza described was very similar to the problems she had had in the first year: there was no brief designed for part-time students; no understanding that last minute time changes made it hard for students to plan their time and, finally, information was not made explicit on Moodle. The VLE had not been used to create a virtual community of friends and did not seem as effective a way of sharing experiences as the physical engagement and immersion in the learning space had been for other students.

\section{Discussion}

For Ricoeur, (1994) phronesis aims at the ethical intention of living, 'the good life with and for others in just institutions', where people of practical wisdom are of good character and are concerned with friendship, justice, courage, moderation and generosity.

It could be seen that Eliza had made a courageous, but considered decision to study textiles part-time so that ultimately she could live a better life that gave more opportunities to be creative. She was following her dreams of being artistic in her career as well as in her leisure time.

However, studying textiles part-time was actually very challenging; perhaps Eliza could not have fully anticipated the problems she would encounter during the six years of her degree. The organisation and management of the part-time mode of the course was not fully understood by Eliza. She was not able to find the information she needed on the VLE to compensate for missing sessions. Basic understanding about the way work was assessed had not been confirmed by the tutors. They also seemed unable to communicate with Eliza effectively. Eliza perhaps did not have the time to experiment with processes and materials 
so that she could develop creative ideas. But what came across in Eliza's narrative was that she thought carefully about how to resolve these issues. She was able to weigh up possibilities, consulting many sources of information such as the learning outcomes; previous feedback; the advice of tutors and the help of other students. She was attempting to draw upon her practical wisdom and her previous experiences of learning so that she could succeed in the context of higher education.

Eliza had reasoned that going through the student representative would instigate positive change. However, this approach was not successful; the students are not being encouraged to act with phronesis because their attempts at improving their situation are continuously being stifled. People can learn to deliberate wisely by being in the presence of a phronimos (Broadhead and Gregson, 2018). In this case Eliza had not often experienced seeing her tutors practise phronesis as they did not share their thought processes with her; communication generally was restricted. For example the motives as to why the tutor felt Eliza should stay on the course were not explored fully; the reasoning appeared to lack transparency and openness.

The actions of the student who made a CAD guide for Eliza demonstrated the capacities of people to support one another. This course of action, to help Eliza out, was motivated by the virtue of kindness or friendship (Nussbaum, 2001). Ricoeur (1994) explored the possibility of mutual friendship between self and other, seeing the relationship as fragile, but an important aspect of phronesis. Students find courage to empower themselves through the bonds of friendship (Duckworth, 2014). The social networks and experiences they encounter allow them to go beyond their previous experiences which sometimes result in symbolic violence and trauma, for the best interests of themselves and others (Duckworth, 2014).

\section{Conclusions}

The method of narrative inquiry, carried out over three years, revealed how Eliza thought about and responded to various issues over time. The consequences or impact of her actions were also suggested from her narratives, for example how study part-time had meant she often had to work late and at unsociable hours. In some instances the ways in which she responded to the ever changing demands made on her from work and her educators were illuminated. It showed that phronesis, as a means of 
coping with the difficulties of being a mature student, was only at times possible. Good deliberation by the student was occasionally impeded by the processes and conventions of higher education within this particular context.

Eliza used the process of telling her story about her experiences as a means of re-establishing what her hopes and dreams were in relation to why she was studying to be a textile designer. Part of the recounting of her story was that she sometimes needed to modify her life plan; her future aspirations in order to cope with the contradictions and uncertainties of time. So there were occasions when she considered dropping out of her course, in light of the difficulties she was facing. Her educational experiences did not seem to increase her confidence in her own abilities in spite of doing well as seen from the range of marks she had achieved. In particular, Eliza's sense of agency as seen through her ability to practice phronesis seemed to be diminished. The marks at level five contributed towards the final degree classification so this could have added to Eliza's anxiety about achieving on her course. It seemed that as the demands of life and her education caused Eliza to be anxious and unconfident, her ability to practice phronesis was diminished. She was not able to temper her frustrations so she could see her aptitudes and achievements clearly.

Eliza's initial decision to study textiles after her Access to HE course was a potentially transformative course of action. However, at this stage in Eliza's story it is difficult to see what kind of impact her experiences of higher education will have on her life. At the very least Eliza demonstrated the capacities of resilience, tenacity and on occasion phronesis or wise deliberation. However, will these abilities be nurtured and developed as Eliza continues with her education? So far her deliberations have led to mixed results because the issues she has experienced have not been resolved.

Further work is still needed on identifying the ways educators could encourage and celebrate phronesis or wise judgments so that students feel they have agency over their own learning. It seems that the confidence needed to be a self-directed learner, one of the aims of higher education, can be reduced, if a student feels under pressure to succeed whilst managing other responsibilities associated with part-time working. Strategies need to be devised that enable students to share their anxieties with staff and peers without being made to feel they are failing. Accepting a mix of students with different educational histories and ages onto a design degree can facilitate intergenerational friendships; the impact of this on their creativity and innovation needs to be investigated further. 


\section{References}

Aristotle. (1953), Nicomachean Ethics in Ethics of Aristotle, Penguin Putnam Trade, Middlesex.

Baumeister, R. and Leary, M. (1995), "The need to belong: desire for interpersonal attachments as a fundamental human motivation"Psychological Bulletin, Vol.117, pp. 497-529.

Bhagat, D. and O'Neill, P. (eds) (2011), Inclusive Practices, Inclusive Pedagogies, ADMA/CHEAD/ACE, London.

Biesta, G. (2010), Good Education in An Age of Measurement: Ethics, Politics, Democracy, Paradigm Publishers, Boulder.

Broadhead, S. (2014), "Inclusion, democracy and the pedagogised other in art and design higher education", Enhancing Learning in the Social Sciences, Vol. 6 No. 1, pp. 42-55.

Broadhead, S. and Gregson, M. (2018), Practical Wisdom and Democratic Education - Phronesis, Art and Non-traditional Students, Macmillan Palgrave, London.

Burke, P. (2002), Accessing Education: Effectively Widening Participation, Trentham Books, Stoke-onTrent .

Busher, H., James, N. and Suttill, B. (2012), Opening Doors to Higher Education: Access Students' Learning Transitions, University of Leicester, Leicester .

Butler-Kisber, L. (2010), Qualitative Inquiry: Thematic, Narrative and Arts-Informed Perspectives, Sage Publications Ltd, London.

Brookfield, S. (1995), Becoming a Critically Reflective Teacher, Jossey-Bass, California.

Coffield, F. (2006), Just Suppose Teaching And Learning Became The First Priority, Learning and Skills Network, London.

Clandinin, D. \& Connelly, F. (2004), Narrative Inquiry: Experience and Story in Qualitative Research, Jossey Bass, San Francisco .

Duckworth, V. (2014), Learning Trajectories, Violence and Empowerment amongst Adult Basic Skills Learners, Routledge, New York.

Ebdon, L. (2018), "Further decline in part-time student numbers "a profound concern"”, available at: https://www.offa.org.uk/press-releases/decline-part-time-student-numbers-profound-concern-lesebdon/ (accessed 08 February 2018).

Goodenow, C. (1993), "The psychological sense of school membership among adolescents: scale development and educational correlates", Psychology in the Schools, Vol. 30 No. 1, pp. 70-90. 
Hudson, C. (2009), Art from the Heart: The Perceptions of Students from Widening Participation Backgrounds of Progression to and through HE Art and Design, National Arts Learning Network, London.

Liasidou, A. (2012), Inclusive Education, Politics and Policymaking, Continuum, London .

Maclntyre, A. (2007), After Virtue: A Study in Moral Theory. 3rd Revised ed., Gerald Duckworth and Co Ltd, London.

Nussbaum, M.C. (2001), The fragility of goodness, Cambridge University Press, Cambridge.

Penketh, C. and Goddard, G. (2008), "Students in transition: mature women students moving from foundation degree to honours level 6", Research in Post-Compulsory Education, Vol. 13 No.3, pp. 315327.

Ricœur, P. (1994), Oneself as Another, University of Chicago Press, Chicago .

Sennett, R. (2008), The Craftsman, Yale University Press, New Haven .

Skilleås, O.M. (2006), "Knowledge and imagination in fiction and autobiography", Metaphilosophy, Vol. 37 No. 2, pp. 259-276.

Thomas, L. (2002), "Student retention in higher education: the role of institutional habitus", Journal of Education Policy, Vol. 17 No. 4, pp. 423-432.

Thomas, P.L. (2012), "Building Student Engagement and Belonging in Higher Education at a Time of Change: Final Report from the What works? Student Retention and Success Programme", available at: http://www.heacademy.ac.uk/resources/detail/retention/What works final report (accessed 10 July 2014).

Tinto, V. (1993), Leaving College: Rethinking the Causes and Cures of Student Attrition, University of Chicago Press, Chicago.

Wall, J. (2005), "Phronesis as poetic: moral creativity in contemporary aristotelianism", The Review of Metaphysics, Vol. 59, pp. 313-331.

Wilcox, P., Winn, S., \& Fyvie-Gauld, M. (2005), "It was nothing to do with the university, it was just the people: the role of social support in the first year experience of higher education", Studies in Higher Education, Vol. 30 No 6, pp. 707-722.

Williams, J. (2013), Consuming Higher Education: Why Learning Can't Be Bought, Bloomsbury Academic, an imprint of Bloomsbury Publishing Plc, London. 